\title{
Carrageenan-Induced Inflammation and Its Effects on Mitotic Activity and Keratinization of Gingival Epithelium*
}

\author{
A Histologic and Autoradiographic Study
}

\author{
Raul G. Caffesse,† Carlos E. Nasjletił and Charles J. Kowalski§
}

Accepted for publication 15 May 1984

\begin{abstract}
THIS STUDY WAS UNDERTAKEN in order to: (1) evaluate the cell population in carrageenaninduced inflammation and (2) investigate the extent to which this inflammation modified mitotic activity, and keratinization of the sulcular epithelium induced by daily prophylaxes in monkeys. Normal-keratinized oral gingival epithelium was also evaluated for these processes in the same gingival specimens. Each of three adult Rhesus monkeys received a thorough prophylaxis 1 week prior to the experiment. Over the 10-week experimental period, each monkey received daily rubber cup prophylaxes. In addition, during the last 10 days, daily gingival injections of a $1 \%$ carrageenan saline solution and normal saline solution were given. One hour prior to sacrifice, each monkey received an intravenous injection of tritiated thymidine, $1 \mu \mathrm{Ci} / \mathrm{gram}$ of body weight. After sacrifice and tissue processing, the histologic sections were evaluated. It was found that the carrageenan solution injected into gingival tissues produced an acute inflammatory response consisting of polymorphonuclear leukocytes PMNs $(61.3 \%)$, lymphocytes $(5.2 \%)$, monocytes/macrophages $(23.5 \%)$, plasma cells $(2.0 \%)$ and unidentified cells (3.8\%). An Inflammatory Index and a Mitotic Activity Index were determined, and keratin length and widths were measured. Data were analyzed statistically using analysis of variance. Pairwise comparisons were also made using Scheffe's method of multiple comparisons. The study showed that: (1) carrageenan solutions injected into gingival tissues elicited an acute inflammation; (2) acute inflammation present in gingival connective tissue stimulated an increase in mitotic activity in subjacent gingival epithelium; (3) acute inflammation within gingival tissues did not modify the inducedkeratinized sulcular epithelium, or the normally-keratinized oral gingival epithelium; and (4) acute inflammation may not necessarily affect tissue keratinization, if bacterial plaque is removed daily.
\end{abstract}

Numerous histologic and autoradiographic studies have been done in gingival tissues to determine if a relationship exists between the degree of connective tissue inflammation and epithelial proliferation, ${ }^{1-10}$ or surface keratinization. ${ }^{10-14}$ The presence of inflammation was shown to be associated with an increase in epithelial mitotic activity in the gingiva of humans, ${ }^{1-4}$ rats ${ }^{5}$ and monkeys. ${ }^{6-9}$ Mitotic activity of the epithelium overlying infiltrated connective tissue was significantly

* This investigation was partially supported by the Medical Research Division of the Veterans Administration.

$\dagger$ Professor and Chairman, Department of Periodontics, The University of Michigan School of Dentistry, Ann Arbor, MI 48109.

$\ddagger$ Coordinator, Dental Research Program, Veterans Administration Medical Center, Ann Arbor, MI 48105.

$\S$ Professor of Dentistry and Research Scientist in the Dental Research Institute, School of Dentistry, The University of Michigan. greater than that overlying normal connective tissue. Further, it was shown that mitotic activity in gingival epithelium was related to the extent of, and the composition of the connective tissue infiltrates. ${ }^{9}$ However, in a study undertaken to evaluate the possible relationship between connective tissue inflammation, epithelial mitotic activity and keratinization in the gingiva of Rhesus monkeys, ${ }^{10}$ the severity of inflammation was not related to the mitotic activity of the adjacent epithelium, but was inversely related to the degree of keratinization. It has also been shown that a decrease in keratinization was associated with underlying connective tissue inflammation. ${ }^{11-13}$ However, in a study designed to evaluate the effect of dextran-induced chronic inflammation on gingival keratinization, it was found that inflammation may not necessarily affect keratinization, if thorough removal of bacterial plaque was well maintained. ${ }^{14}$ 
A number of recent studies from this laboratory have demonstrated that: (1) systemic antibiotics and local prophylaxes, as single agents or in combination, were effective in reducing inflammation within the gingival tissues; (2) the reduction in inflammation obtained by either method allowed sulcular epithelium keratinization to develop; (3) this keratinization was significantly increased by performing daily subgingival prophylaxes; and (4) mechanical stimulation of the gingival sulcular epithelium seemed to promote keratinization. ${ }^{14-16}$

It has been demonstrated that the algal polysaccharide, carrageenan, induced acute inflammation when injected in the rat hindlimb. ${ }^{17}$ When it was injected repeatedly over a 3- to 6-month period, the repeated acute inflammation, however, did not lead to chronic inflammation. ${ }^{18}$ Acute inflammatory responses were also demonstrated when carrageenan was injected into the pleural or peritoneal cavity of the rat. ${ }^{19}$ Carrageenan-induced acute inflammation caused a significant increase in the percentage of binucleated keratinocytes in guinea pig palatal epithelium. ${ }^{20}$

This study was undertaken in order to: (1) evaluate the cell population in carrageenan-induced inflammation and (2) investigate the extent to which this inflammation modified both mitotic activity, and keratinization of the sulcular epithelium induced by daily prophylaxes in monkeys. Normally keratinized oral gingival epithelium was also evaluated for these processes in the same gingival specimens.

\section{MATERIALS AND METHODS}

Three healthy adult male Rhesus monkeys (Macaca mulatta) having complete dentitions with moderate supra- and subgingival calculus and moderate marginal gingivitis were used. One week prior to the experiment, all teeth were thoroughly scaled and polished. All animals received IV tetracycline hydrochloride (Achromycin $^{\left({ }^{(R)}\right)}$ at dosage of $20 \mathrm{mg} / \mathrm{kg}$ body weight, daily, for 1 week. At the end of the pre-experimental week, all three monkeys began the first stage of a two-stage experimental regime. It consisted of daily rubber cup prophylaxes accomplished by polishing with a prophylaxis paste $\left(\mathrm{Nupro}^{\mathrm{iR}}\right)$. Such treatments were performed during the 5 weekdays only, for 10 weeks.

At the end of the 8th week, one gingival biopsy from each of the three monkeys was taken and used to determine sulcular induced-keratinization. Since the biopsies showed keratinization, the second experimental stage was started. During the continuation of prophylaxes, $200 \mu \mathrm{l}$ of $1 \%$ carrageenan in saline was injected into the gingival tissues, buccally and lingually, in one quadrant of each monkey. Lambda-carrageenan* a nongeling form was used. Physiological saline $(200 \mu \mathrm{l})$ injected into the gingival tissues in a different quadrant, served as the control. A third quadrant was

\footnotetext{
* Sigma Chemical Co. St. Louis, MO.
}

used as an uninjected control. The fourth quadrant in each monkey was used as a duplicate of one of the above mentioned treatments. In each quadrant, the gingival tissues of the bicuspids, first and second molars were used. Injections were repeated for 10 days, at which time the animals were sacrificed. Following anesthetization with pentobarbital sodium, the monkeys received, by intravenous injection, a dosage of tritiated thymidine $+1 \mu \mathrm{Ci} / \mathrm{gm}$ body weight (Specific Activity $6.7 \mathrm{mmol}$ ). All animals were sacrificed 1 hour after the thymidine injection. The heads were dissected, fixed in $10 \%$ buffered formalin solution, and decalcified in $20 \%$ formic acid. Specimens were embedded in paraffin, sectioned buccolingually at $6 \mu \mathrm{m}$ intervals, and mounted on glass slides. Every fifth slide or tissue section was processed for autoradiographic evaluation using Kodak's nuclear track emulsion, $\$$ type NTB-3, according to the dipping technique of Joftes. ${ }^{21}$ The remaining slides were stained with either Harris's hematoxylin and eosin ${ }^{22}$ or Rhodamine $\mathrm{B}^{23} \mathrm{~A}$ total of 1,152 microscopic slides were evaluated for the study. Of these, 384 slides prepared for autoradiographic evaluation were used for counting tritiated thymidine labeled epithelial basal cells, 128 per monkey, 32 per quadrant; 384 slides stained with Rhodamine B were used for measuring keratin; and an equal number of slides stained with hematoxylin and eosin were used for identification and counting of inflammatory cells present in connective tissue.

Autoradiographic Evaluation. Autoradiographs were examined using a binocular microscope at $100 \times$ magnification. Labeled epithelial basal cells were counted at three different zones (Fig. 1). Zone A (the sulcular epithelium crestal zone) included the coronal one-half of the sulcular epithelium and its subjacent connective tissue. Zone B (the sulcular epithelium cervical zone) was comprised of the remaining one-half of the sulcular epithelium extending to the beginning of the junctional epithelium. Zone $\mathrm{C}$ (the oral gingival epithelium zone) included the oral gingivae at the level corresponding to the boundary separating Zone A and Zone B. These zones were evaluated on each of the 384 slides by selecting one microscopic field in each zone. This field represented, at $100 \times$ magnification, a rectangle of 100 $\times 69 \mu \mathrm{m}$. In these fields, labeled epithelial cells were counted using a Veeder§ hand tally counter, and the value was recorded. In each quadrant, a Mitotic Activity Index was obtained by using these values, as previously described. $^{8}$

Histologic Evaluation. Rhodamine B stained slides were evaluated for the determination of the presence or absence of keratin in the previously described zones: A, $\mathrm{B}$ and $\mathrm{C}$. In Zones A and B combined, the length and width of the keratin layer, if present, was measured

\footnotetext{
† New England Nuclear, Boston, MA.

$\ddagger$ Eastman Kodak Co. Rochester. NY.

$\S$ Veeder Root Vue, Hartford, CT.
} 


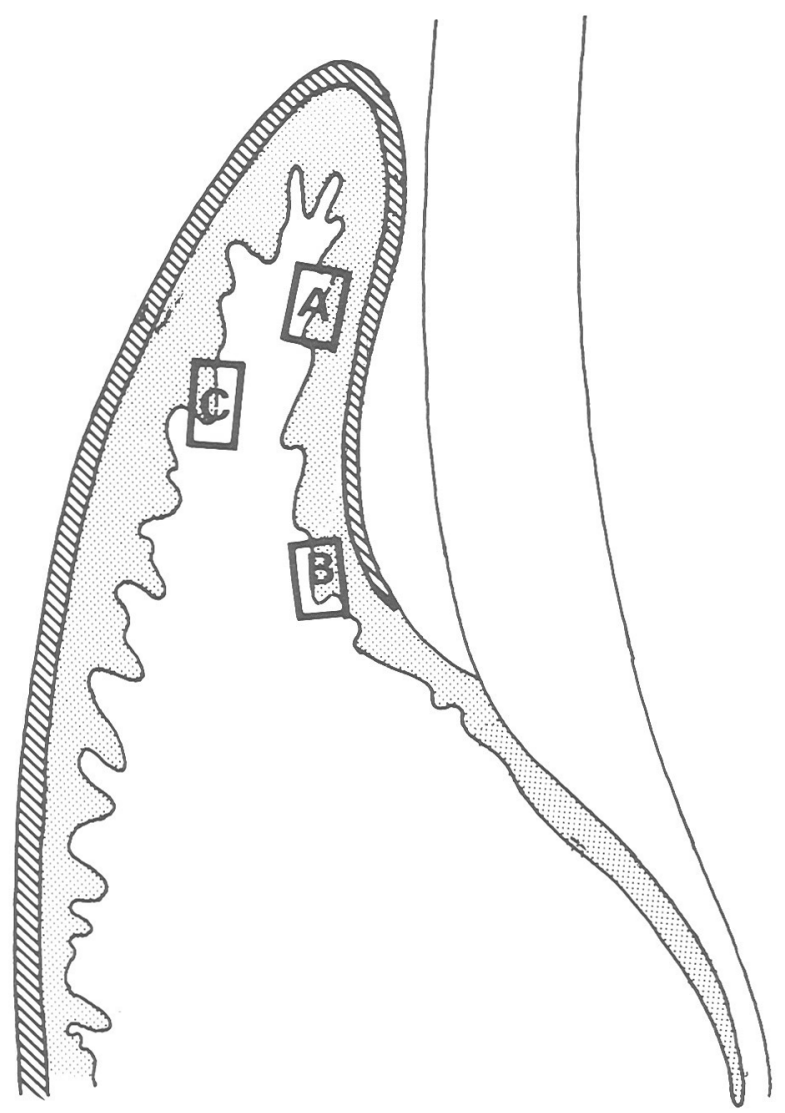

Figure 1. Diagram showing the location of the three zones $A, B$ and $C$ where the histologic and autoradiographic evaluations were performed.

using a Filar Micrometer Eyepiece.* In Zone C (oral gingival epithelium zone) the width of the keratin was similarly measured. ${ }^{15}$ The degree of inflammation in the connective tissue subjacent to epithelial Zones A, B and $C$ was also evaluated. An Inflammatory Index was obtained for each zone by counting the number of inflammatory cells present within a microscopic field, as previously described. ${ }^{15}$ Cell identification was also performed based on previously reported morphological criteria relating to nuclear shape and cell size. ${ }^{24}$ Inflammatory cells included monocytes, macrophages, lymphocytes, plasma cells, polymorphonuclear leukocytes (PMNs), and unidentified cells. In addition, normal fibroblasts present in connective tissues were also counted in order to determine if any relationship existed between them and the inflammatory cells.

Statistical Analysis. The individual values recorded in each slide for mitotic activity, inflammation, and keratin length and widths were used to determine a mean value for each quadrant in each monkey. These "means per quadrant" values were used to compute an overall mean for each parameter mean, in each treatment group. The mean values for the Mitotic Activity Indices, Inflammatory Indices, and Keratin Length and

* Bausch and Lomb, Rochester, NY.
Keratin Widths in the carrageenan, saline and control groups were compared using analysis of variance. Pairwise comparisons were made using Scheffe's method of multiple comparisons. Correlation coefficients were also computed to see whether the parameters tested were at all related. For statistical analysis the number of animals used was considered as the statistical unit.

\section{RESULTS}

After the experimental procedures, the gingiva of the uninjected control quadrants remained clinically healthy with firm, pink, and knife-edged gingival margins. The gingiva of the normal saline-injected control quadrants appeared rounded and evidently inflamed, whereas the carrageenan-injected quadrants demonstrated gingival enlargement. This edematous gingiva bled easily upon slight provocation.

Histologic examination of the gingival tissues demonstrated an ortho- or para-keratinized band covering not only the oral gingival epithelium but also the sulcular epithelium. Rete ridges were prominent in the sulcular epithelium to such an extent that the dimensions and morphology of this epithelium were comparable to those of the oral gingival epithelium (Fig. 2A). In uninjected control specimens, although histologically normal, a minimal or residual inflammatory cell infiltration was evident in the connective tissue adjacent to the sulcular and junctional epithelium (Fig. 2A). Connective tissues in gingival specimens injected with normal physiological saline solution demonstrated: (1) vasculitis of vessels and a partial loss of collagen fiber network supporting the marginal gingiva, (2) cytopathic alterations in resident fibroblasts and (3) an increased migration of leukocytes into the injected marginal gingiva. Gingival specimens injected with carrageenan solution showed: (1) the fiber bundles of the marginal gingiva lost their characteristic orientation and architecture completely; (2) superimposed upon this picture is a dense infiltrate of inflammatory cells, mainly PMNs; and (3) a total loss of collagen is apparent in the zone of cellular infiltration (Fig. 3A).

In these gingival specimens the cell population present in connective tissues was estimated; the results are presented in Table 1. However, since the primary objective of the present study was to relate the number of inflammatory cells to the connective tissue background in an expression of the relative severity of the carrageenan-induced inflammation, inflammatory cells were grouped into a single category for the purpose of obtaining the Inflammatory Indices.

The mean values for the Inflammatory Indices (II), Mitotic Activity Indices (MAI), Keratin Length (KL) and Keratin Widths (KW) are presented in Table 2. Analysis of variance showed significant differences for the II in each of the three zones considered. Pairwise comparisons were then made and each of the groups 

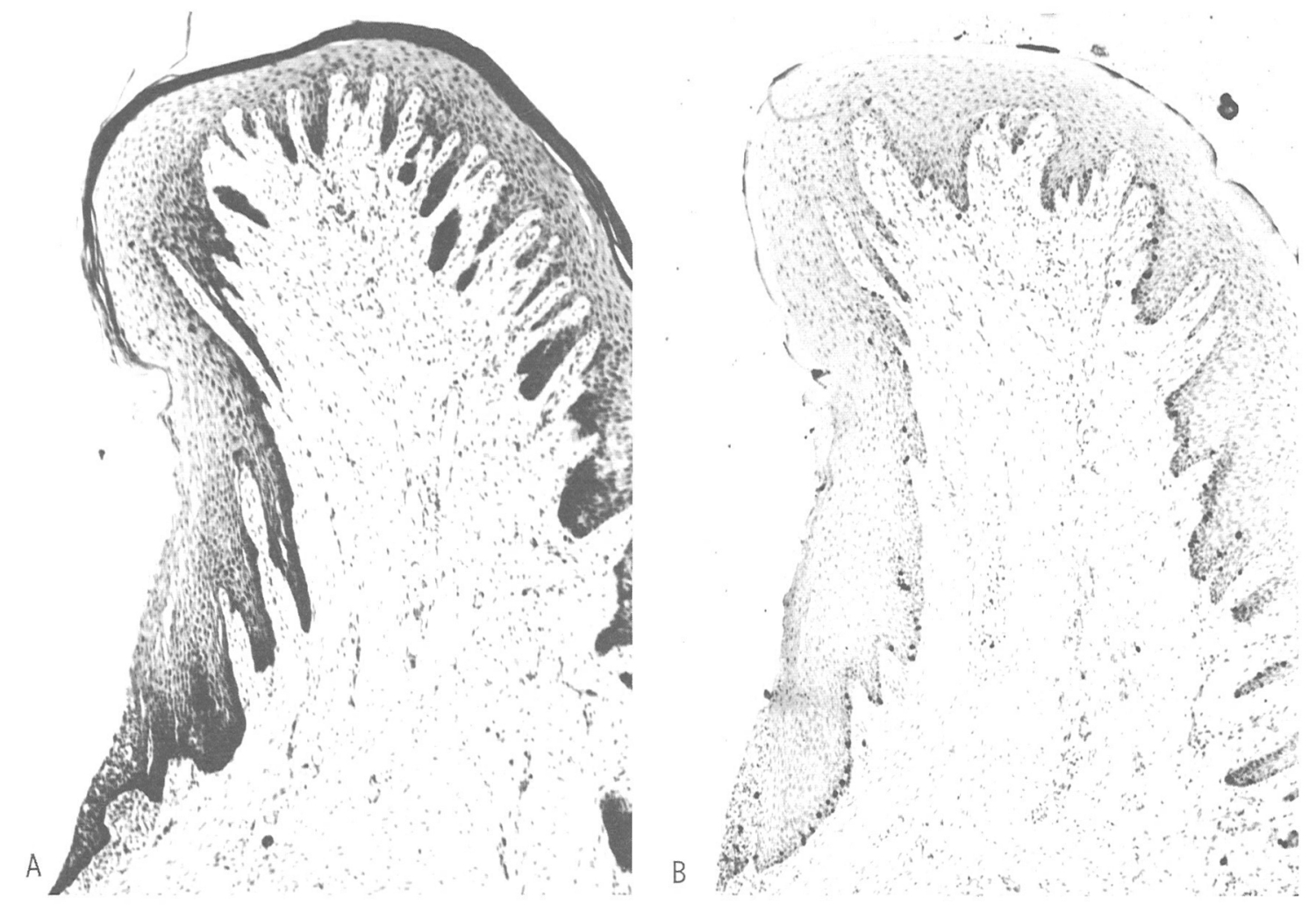

Figure 2. A, control uninjected gingival specimen showing a minimal or residual inflammatory cell infiltration. $\boldsymbol{B}$, autoradiograph serial section of $A$ (Rhodamin B stain, magnification $\times 40$ ).

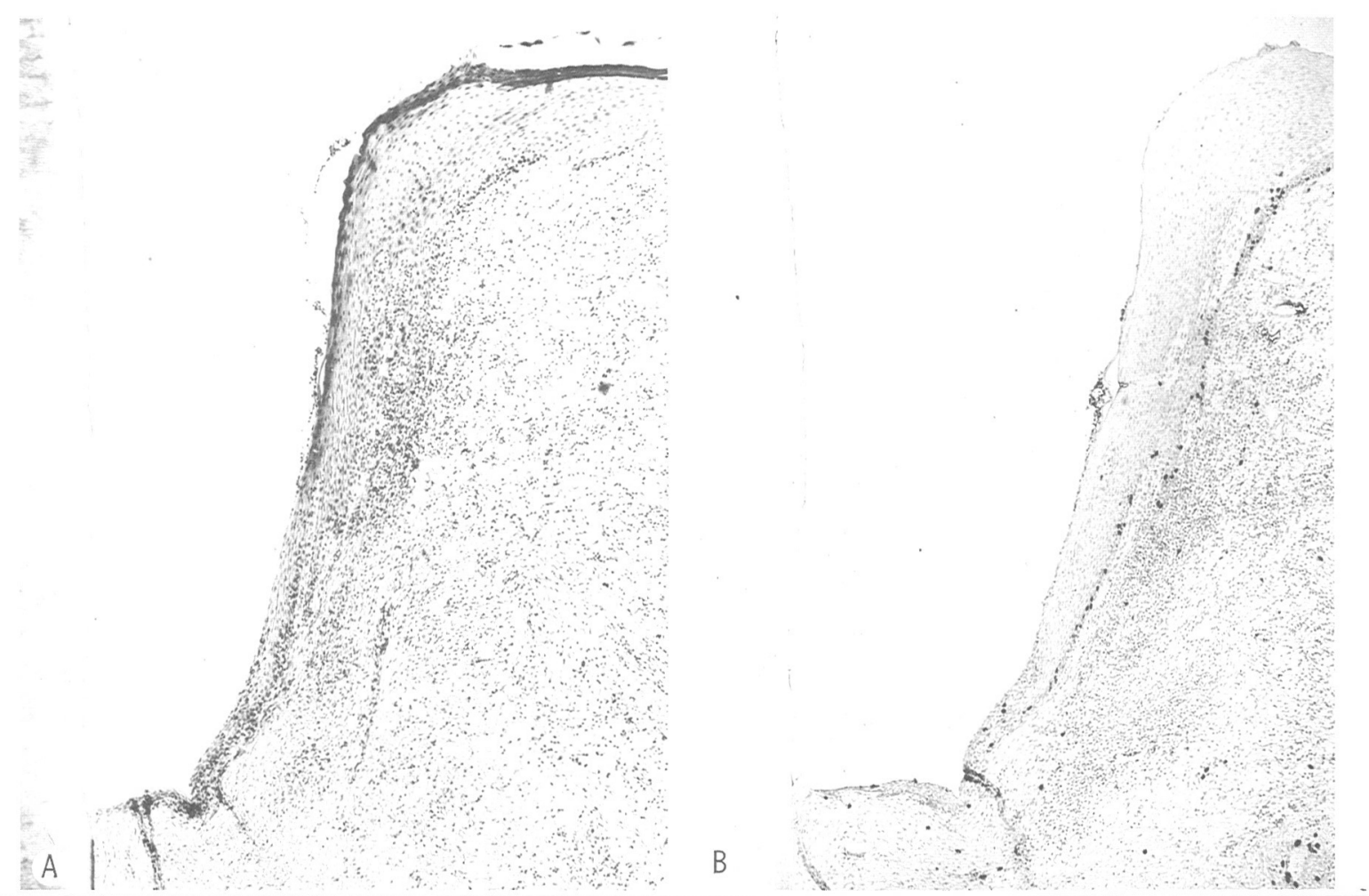

Figure 3. A, carrageenan-injected gingival specimen showing induced inflammation. B, autoradiograph serial section of $\boldsymbol{A}$ showing labeled epithelial basal cells and adjacent connective tissue inflammation (Hematoxylin and eosin stain, magnification $\times 50$ ).

was significantly different from one another $(P<0.05)$ in Zones $\mathrm{A}$ and $\mathrm{C}$. In Zone $\mathrm{B}$, the carrageenan group differed from the control but none of the other pairwise comparisons proved to be statistically significant. Nor 
were the three MAI different in the three groups. One can note, however, that the same pattern of responses was observed as for the II. In all zones, the MAI were highest in the carrageenan group, had intermediate values in the normal saline group, and were lowest in the control group (Figs. 2B and 3B).

Keratin Length was significantly different in the three groups using the analysis of variance $(P=0.03)$ but the only significant pairwise comparison was that between the carrageenan and the saline groups. Keratin Width was found to differ in the saline and control groups. In Zone $\mathrm{C}$, differences between the three groups were nonsignificant. Correlation coefficients were also computed to determine if the MAI and the II were related. The respective correlations in Zones A, B and C were $0.73,0.76$ and 0.49 showing that increases in one of the indices is generally accompanied by an increase in the other. Keratin Width on the other hand, was negatively correlated with each of the indices in all three zones, i.e., the higher the levels of MAI and II, the lower the formation of keratin.

\section{DISCUSSION}

Our finding, regarding the presence of a minimal or residual inflammatory infiltrate in connective tissue of control uninjected gingival specimens from monkeys receiving oral prophylaxes, is not too surprising. In previous studies, inflammatory cells were regularly found in healthy gingivae of humans, ${ }^{25-27}$ monkeys ${ }^{28.29}$ and dogs..$^{30,31}$ Inflammatory cell infiltration into gingival connective tissues has been found to occur even in germ-free animals. ${ }^{32,33}$

Table 1

Estimated Percentages of the Cell Population Present in Uninjected and Injected Gingival Specimens

\begin{tabular}{lccc}
\hline \multicolumn{1}{c}{ Cell types } & $\begin{array}{c}\text { Uninjected, } \\
\text { normal } \\
\text { control }\end{array}$ & $\begin{array}{c}\text { Injected, } \\
\text { normal } \\
\text { saline }\end{array}$ & $\begin{array}{c}\text { Injected, } \\
\text { carrageenan } \\
\text { saline }\end{array}$ \\
\hline Fibroblasts & 77.7 & 43.8 & 4.2 \\
PMNs & 3.0 & 33.5 & 61.3 \\
Monocytes/macrophages & 5.0 & 9.0 & 23.5 \\
Lymphocytes & 9.3 & 10.0 & 5.2 \\
Plasma cells & 3.0 & 2.0 & 2.0 \\
Unidentified cells & 2.0 & 1.7 & 3.8 \\
\hline
\end{tabular}

Table 1 illustrates the effect of injecting normal saline and carrageenan solutions on gingival cell population. Both experimental solutions effectively changed the cell population so that PMNs as well as monocytes/macrophages tended to increase, while lymphocytes and plasma cells remained at the level of control specimens or were markedly reduced. Clearly, carrageenan seemed to have a pronounced effect on the proportion of cell types present in the injected tissues. In these tissues around $62 \%$ of the cell population was comprised of PMNs and $24 \%$ of monocytes/macrophages. Injected carrageenan in gingival tissues produced a frank acute inflammatory reaction. This result is compatible with the findings of other investigators who have used carrageenan to provoke acute inflammation. ${ }^{17-20}$ However, results from studies involving the complement system seem to contradict these findings. The effect of serum decomplementation by carrageenan on the emigration of PMNs and monocytes into the dog gingival crevices has been evaluated. ${ }^{34.35}$ Decomplementation by carrageenan resulted in a pronounced decrease in the number of junctional PMNs and monocytes. Carrageenan was simultaneously injected in doses of $80 \mathrm{mg} / \mathrm{kg}$ body weight intraperitoneally, and $25 \mathrm{mg} / \mathrm{kg}$ body weight intravenously. The conflicting results may be accounted for by differences in the animal model, differences in the route or mode of carrageenan administration, or by differences in the amount injected.

Under the influence of persistent acute inflammation in the gingival tissues, produced by carrageenan, the collagen-dense and fibroblast-rich connective tissue was converted into a tissue extremely poor in collagen and fibroblasts, and high in PMNs and monocytes/macrophages. PMNs and monocytes constitute the major line of defense against all forms of injury and microbial challenge around teeth and throughout the body. These cells carry out their important protective function by moving chemotactically to appropriate sites, phagocytizing, killing and digesting microorganisms, and engulfing and destroying noxious substances and damaged tissue. ${ }^{36-38}$ In addition to providing protection against foreign challenge, PMN's and monocytes have the capacity to participate in an important way in tissue destruction. These cells carry potent acid hydrolases,

Table 2

Mean Values for the Inflammatory Indices (II), Mitotic Activity Indices (MAI), Keratin Length (KL) and Keratin Widths (KW) in the Zones Considered (ANOVA)

\begin{tabular}{|c|c|c|c|c|c|c|c|c|c|}
\hline & II A & II B & II C & MAI A & MAI B & MAI C & $\mathrm{KL}$ & $\mathrm{KW} \mathrm{AB}$ & KW C \\
\hline Carrageenan* & $\begin{array}{l}91.87 \\
(7.76) \dagger\end{array}$ & $\left.\begin{array}{c}84.83 \\
(4.13)\end{array}\right]$ & $\begin{array}{l}34.53 \\
(1.10)\end{array}$ & $\left.\begin{array}{c}27.50 \\
(7.25)\end{array}\right]$ & $\left.\begin{array}{l}31.83 \\
(7.35)\end{array}\right]$ & $\left.\begin{array}{c}20.03 \\
(10.13)\end{array}\right] T$ & $\begin{array}{c}6.25 \\
(0.23)\end{array}$ & $\left.\begin{array}{c}0.32 \\
(0.01)\end{array}\right]$ & $\begin{array}{c}0.37 \\
(0.004)\end{array}$ \\
\hline Saline & $\begin{array}{l}55.83 \\
(3.17)\end{array}$ & $\begin{array}{l}38.59 \perp \\
(3.46)\end{array}$ & $\begin{array}{l}17.13 \\
(0.87)\end{array}$ & $\begin{array}{l}23.17 \frac{1}{\top} \\
(1.96)\end{array}$ & $\begin{array}{l}27.63 \frac{1}{\top} \\
(3.29)\end{array}$ & $\begin{array}{l}16.27 \stackrel{\perp}{\top} \\
(0.90)\end{array}$ & $\begin{array}{c}5.37 \\
(0.24)\end{array}$ & $\begin{array}{c}0.29 \perp \\
(0.03)\end{array}$ & $\begin{array}{c}0.35 \\
(0: 03)\end{array}$ \\
\hline Control & $\begin{array}{l}27.97 \\
(2.40)\end{array}$ & $\begin{array}{l}17.37 \perp \\
(0.76)\end{array}$ & $\begin{array}{c}8.83 \\
(0.61)\end{array}$ & $\begin{array}{l}19.97 \\
(3.10)\end{array}$ & $\begin{array}{l}23.80 \perp \\
(7.08)\end{array}$ & $\begin{array}{l}13.80 \perp \perp \\
(4.31)\end{array}$ & $\underset{(0.43)}{6.15} \perp \perp$ & $\begin{array}{c}0.37 \\
(0.03)\end{array}$ & $\begin{array}{c}0.39 \\
(0.004)\end{array}$ \\
\hline
\end{tabular}

IIndicates no significant difference (Scheffe's procedure) $P<0.05$.

* For each of the three experimental groups, 384 slides or tissue sections were evaluated.

+ Standard deviations in parentheses. 
collagenases, prostaglandins and other substances having the capacity to destroy collagen and other connective tissue substances. ${ }^{37-39}$ Collagenolytic activity of in vitro explants has been studied. ${ }^{40}$ In that study, for the preparation of the explants, a $1 \%$ solution of carrageenan in normal saline was injected subcutaneously in the abdominal wall of guinea pigs and rabbits, 5 and $15 \mathrm{ml}$, respectively. These injections elicited a local response, called granuloma; however, the cell population is characterized by an increased number of PMNs and macrophages. The study showed that collagen resorption resulted from a macrophage-related collagenase activity. ${ }^{40}$

The data in Table 2 show that although not statistically significant, the presence of carrageenan-induced acute inflammation causes an increase in the mitotic activity of the adjacent gingival epithelium. This finding agrees with the results of others who have shown that the presence of inflammation stimulated mitotic activity. ${ }^{1-9}$ However, there is an unconfirmed study showing that no relationship exists between mitotic activity of the gingival epithelium and the severity of inflammation in the connective tissue area. ${ }^{10}$

Table 2 also shows that carrageenan-induced acute inflammation did not modify the normally-keratinized oral gingival epithelium, or the induced-keratinized sulcular epithelium. We reported recently that similar results were obtained when dextran solutions were injected into gingival tissues of monkeys. ${ }^{14}$ Dextran-induced chronic inflammation did not affect keratinization when bacterial plaque was removed daily. These findings strongly suggest that the control of acute or chronic inflammation within the gingival tissues is not as critical as the removal of bacterial plaque. Evidence, in support of this notion, comes from clinical studies in humans which showed that no significant differences were observed during the development of inflammation in areas with or without attached gingiva. ${ }^{4-46}$ Similar evidence is seen in studies using dogs, ${ }^{47.48}$ monkeys ${ }^{49}$ and miniature swines. ${ }^{50}$ The authors concluded that a rationale to increase the width of gingiva to provide a fibrous barrier to inflammation did not seem prudent. It appears, therefore, that little, if any, keratinized gingiva is necessary for the maintenance of gingival health, if plaque control is well maintained.

\section{CONCLUSIONS}

Within the limits of this study it may be concluded that:

1. Carrageenan in solution injected into gingival tissues produced an acute inflammation.

2. Acute inflammation present in gingival connective tissue stimulated an increase of mitotic activity in overlying gingival epithelium.

3. Acute inflammation within gingival tissues did not modify the induced-keratinized sulcular epithe- lium, or the normally-keratinized oral gingival epithelium.

4. Acute inflammation may not necessarily affect keratinization, if bacterial plaque is removed daily.

\section{REFERENCES}

1. Meyer, J., Marwah, A. S., and Weinmann, J. P.: Mitotic rate of gingival epithelium in two age groups. $J$ Invest Dermat 27: 237 . 1956.

2. Marwah, A. S., Weinmann, J. P., and Meyer, J.: Effect of chronic inflammation on the epithelial turnover of the human gingiva. AMA Arch Pathol 69: 147, 1960.

3. Silberkweit, M., Soni, N. N., and Hayes, R. L.: Pattern of mitotic activity and cell densities in the epithelium of inflamed gingivae of children. $J$ Dent Res 42: 1503, 1963.

4. Soni, N. N., Silberkweit, M., and Hayes, R. L.: Pattern of mitotic activity and cell densities in human gingival epithelium. $J$ Periodontal 36: 15, 1965.

5. Mühlemann, H. R., and Hartl, St.: Daily variations of mitotic rate and inflammatory cell migration in the epithelium of the intermolar rat papilla. Bull Schweiz Akad Med Wiss 11: 379, 1955.

6. Skougaard, M. R., and Beagrie, G. S.: The renewal of gingival epithelium in marmosets (Callithrix Jacchus) as determined through autoradiography with thymidine $-\mathrm{H}^{3}$. Acta Odontol Scand 20: 467, 1962.

7. Hopps, R. M., and Johnson, N. W.: Relationship between histological degree of inflammation and epithelial proliferation in macaque gingiva. J Periodont Res 9: 273, 1974.

8. Caffesse, R. G., Kornman, K. S., and Nasjleti, C. E.: The effect of intensive antibacterial therapy on the sulcular environment in monkeys. Inflammation, mitotic activity and keratinization of the sulcular epithelium. J Periodontal 51: 155, 1980.

9. Johnson, N. W., and Hopps, R. M.: Cell dynamics of experimental gingivitis in macaques. The nature of the cellular infiltrate with varying degrees of gingivitis. J Periodont Res 10: 177, 1975.

10. Demetriou, N. A., and Ramfjord, S. P.: Premitotic labeling and inflammation in the gingiva of Rhesus monkeys. $J$ Periodontol 43: 608, 1972.

11. Dewar, M. R.: Observations on the composition and metabolism of normal and inflamed gingiva. $J$ Periodontol 26: 29, 1955.

12. Trott, J. R.: Histological investigation into keratinization found in human gingiva. $B r$ Dent $J$ 103: 421, 1957.

13. Weinmann, J. P., Meyer, J., Mardfin, D., and Weiss, M.: Occurrence and role of glycogen in the epithelium of the alveolar mucosa and the attached gingiva. Am J Anat 104: 381, 1959.

14. Nasjleti, C. E., Caffesse, R. G., and Kowalski, C. J.: Dextraninduced inflammation and its effect on keratinized gingival epithelium in monkeys. J Periodontol 55: 531, 1984.

15. Bye, F. L., Caffesse, R. G., and Nasjleti, C. E.: The effect of different plaque control modalities on the keratinizing potential of the sulcular epithelium in monkeys. $J$ Periodontol 51: 632, 1980.

16. Caffesse, R. G., Nasjleti, C. E., Kowalski, C. J., and Castelli, W. A.: The effect of mechanical stimulation on the keratinization of sulcular epithelium. $J$ Periodontol 53: 89, 1982.

17. Winter, C. A.: Anti-inflammatory testing methods: comparative evaluation of indomethacin and other agents. S. Garantinni and N. G. Dukes, (eds), Non-steroidal Anti-inflammatory Drugs, pp 190202. Amsterdam, Excerpta Medica Foundation, 1965.

18. Vinegar, R., Truax, J. F., and Selph, J. L.: Quantitative studies of the pathway to acute carrageenan inflammation. Fed Proc 35: 2447, 1976.

19. DiRosa, M., Giroud, J. P., and Willoughby, D. A.: Studies of the mediators of the acute inflammatory response induced in rats in different sites by carrageenan and turpentine. $J$ Pathol 104: 15, 1971.

20. Daniel, A., and Fournier, B.: Effect of carrageenan-induced inflammation on the binucleate keratinocytes of guinea pig palatal mucosa. J Periodontol 50: 114, 1979. 
21. Joftes, D. L.: Autoradiography, principles and procedures. $J$ Nucl Med 4: 143, 1963.

22. Lillie, R.: Histopathological Technic and Practical Histochemistry, ed 3, p 174. New York, McGraw-Hill Book Co, 1965.

23. Clausen, F., and Dabelsteen, E.: Increase in sensitivity of the Rhodamine B method for keratinization by the use of the fluorescent light. Acta Pathol Microbiol Scand 77: 169, 1969.

24. Bloom, W., and Fawcett, D. W.: A Textbook of Histology, ed 10, pp 171-182. Philadelphia, W. B. Saunders, 1975.

25. Zachrisson, B. U., and Schultz-Haudt, S. D.: A comparative histological study of clinically normal and chronically inflamed gingivae from the same individuals. Ondontol Tidskr 76: 179, 1968.

26. Schroeder, H. E.: Quantitative parameters of early human gingival inflammation. Arch Oral Biol 15: 383, 1970.

27. Payne, W. A., Page, R. C., Ogilvie, A. L., and Hall, W. B.: Histopathological features of the initial and early stages of experimental gingivitis in man. $J$ Periodont Res 10: 51, 1975.

28. Listgarten, M. A., and Ellegard, B.: Experimental gingivitis in the monkey. Relationship of leukocyte counts in junctional epithelium, sulcus depth, and connective tissue inflammation scores. $J$ Periodont Res 8: 199, 1973.

29. Johnson, N.W., and Kenney, E. B.: Effects of topical application of chlorhexidine on plaque and gingivitis in monkeys. Histologic assessment. J Periodont Res 7: 180, 1972.

30. Attström, R.: Presence of leukocytes in crevices of healthy and chronically inflamed gingivae. $J$ Periodont Res 5: 42, 1970.

31. Listgarten, M. A., Lindhe, J., and Parodi, R.: The effect of systemic antimicrobial therapy on plaque and gingivitis in dogs. $J$ Periodont Res 14: 65, 1979.

32. Magnusson, B.: Mucosal changes at erupting molars in germ free rats. J Periodont Res 4: 181, 1969.

33. Listgarten, M. A., and Heneghan, J. B.: Chronic inflammation in the gingival tissue of germ free dogs. Arch Oral Biol 16: 1207, 1971.

34. Attström, R., and Larsson, U.: Effect of decomplementation by carragheenan on the emigration of neutrophils and monocytes into dog gingival crevices. J Periodont Res 9: 165, 1974.

35. Kahnberg, K.-E., Lindhe, J., and Attström, R.: The effect of decomplementation by carragheenan on experimental initial gingivitis in hyperimmune dogs. J Periodont Res 12: 479, 1977.

36. Page, R. C., and Schroeder, H. E.: Current status of the host response in chronic marginal periodontitis. $J$ Periodontol 52: 477, 1981.

37. Weissmann, G., Zurier, R., Spieler, P., and Goldstein, I.:
Mechanism of lysosomal enzyme release from leukocytes exposed to immune complexes and other particles. J Exp Med 134: 149s, 1971.

38. Lazarus, G. S., Brown, R. S., Daniels, J. R., and Fullmer, H. M.: Human granulocyte collagenase. Science 159, 1483, 1968.

39. Allison, A. C., Ferluga, J., Prydz, H., and Schorlemmer, H. $\mathrm{U}$.: The role of macrophage activation in chronic inflammation. Agents Actions 8: 27, 1978.

40. Perez-Tamayo, R.: Collagen resorption in carrageenin granulomas. Collagenolytic activity in in vitro explants. Lab Invest 22: 137, 1970.

41. Bowers, G.: A study of the width of attached gingiva. $J$ Periodontol 34: 201, 1963.

42. Miyasato, M., Crigger, M., and Egelberg, J.: Gingival conditions in areas of minimal and appreciable width of keratinized gingiva. J Clin Periodontol 4: 200, 1977.

43. Dorfman, H. S., Kennedy, J. E., and Bird, W. C.: Longitudinal evaluation of free autogenous gingival grafts. $J$ Clin Periodontol 7: $316,1980$.

44. De Trey, E., and Bernimoulin, J. P.: Influence of free gingival grafts on the health of the marginal gingiva. $J$ Clin Periodontol 7: $381,1980$.

45. Tenenbaum, H.: A clinical study comparing the width of attached gingiva and prevalence of gingival recessions. J Clin Periodontol 9: 86, 1982.

46. Powell, R. N., and McEniery, T. M.: A longitudinal study of isolated gingival recession in the mandibular central incisor region of children aged 6-8 years. J Clin Periodontol 9: 347, 1982.

47. Wennström, J., Lindhe, J., and Nyman, S.: The role of keratinized gingiva in plaque-associated gingivitis in dogs. $J$ Clin Periodontol 9: 75, 1982.

48. Wennström, $\mathbf{J}$., and Lindhe, J.: Plaque-induced gingival inflammation in the absence of attached gingiva in dogs. $J$ Clin Periodontol 10: 266, 1983.

49. Freeman, E.: Development of the dento-gingival junction of the free gingival graft. J Periodont Res 16: 140, 1981.

50. Kalkwarf, K. L., and Krejci, R. F.: Effect of inflammation on periodontal attachment levels in miniature swine with mucogingival defects. J Periodontol 54: 361, 1983.

Send reprint requests to: Dr. Raul G. Caffesse, Department of Periodontics, School of Dentistry, The University of Michigan, Ann Arbor, MI 48109.

\section{In Memoriam}

\section{Roger Raymond Nolop, DDS 1912-1980}

We have just been informed that Dr. Roger R. Nolop of Mankato, Minnesota, died some time in 1980. He was graduated from the University of Minnesota in 1936 and carried on a general practice until 1959. He then limited his practice to periodontics until his retirement in 1969.

Dr. Nolop served on the Almsted Community Hospital staff in Rochester, Minnesota and St. Joseph's Hospital in Mankato, and served in the US Navy for 3 years. He was a past president of the American Legion in Ortonville, Minnesota.

Dr. Nolop was active in organized dentistry, serving as vice-president of his district dental society in 1953. 